\title{
Characteristics of patients preferring once-daily controller therapy for asthma and COPD: a retrospective cohort study
}

\section{*David Price ${ }^{1,2}$, Amanda J Lee ${ }^{3}$, Erika J Sims ${ }^{2,4}$, Linda Kemp², Elizabeth V Hillyer ${ }^{2}$, Alison Chisholm ${ }^{2}$, Julie von Ziegenweidt ${ }^{2}$, Angela Williams ${ }^{5}$}

\author{
Academic Centre of Primary Care, University of Aberdeen, UK \\ ${ }^{2}$ Research in Real Life, Cambridge, UK \\ ${ }^{3}$ Division of Applied Health Sciences, University of Aberdeen, UK \\ ${ }^{4}$ Norwich Medical School, Faculty of Medicine and Health Sciences, University of East Anglia, Norwich, UK \\ ${ }^{5}$ GlaxoSmithKline R \& D, Uxbridge, UK (currently with Medlmmune, Cambridge, UK)
}

Originally received 7th September 2012; resubmitted 18th November 2012; revised 5th December 2012; accepted 22nd December 2012; online 4th March 2013

\begin{abstract}
Background: Patient preference is an important factor when choosing an inhaler device for asthma or chronic obstructive pulmonary disease (COPD).

Aims: To identify characteristics of patients with asthma or COPD who prefer a once-daily controller medication regimen.

Methods: This retrospective observational study used electronic patient records and linked outcomes from patient-completed questionnaires in a primary care database. We compared the characteristics of patients indicating a preference for once-daily therapy with those who were unsure or indicating no preference.

Results: Of 3,731 patients with asthma, 2,174 (58\%) were women; the mean age was 46 years (range 2-94). Of 2,138 patients with COPD, 980 (46\%) were women; the mean age was 70 years (range 35-98). Approximately half of the patients in each cohort indicated once-daily preference, one-quarter were unsure, and one-quarter did not prefer once-daily therapy. In patients with asthma or COPD, the preference for once-daily controller medication was significantly associated with poor adherence and higher concerns about medication. In asthma, good control and low self-perceived controller medication need were associated with once-daily preference. By contrast, in COPD, a high self-perceived need for controller medication was associated with once-daily preference. There was no significant relationship between once-daily preference and age, sex, disease severity, or exacerbation history.
\end{abstract}

Conclusions: Understanding patient preferences may help prescribers to individualise therapy better for asthma and COPD.

(C) 2013 Primary Care Respiratory Society UK. All rights reserved.

D Price et al. Prim Care Respir J 2013; 22(2): 161-168

http://dx.doi.org/10.4104/pcrj.2013.00017

Keywords adherence, asthma, chronic obstructive pulmonary disease, once-daily, preference, retrospective observational study

\section{See linked editorial by Horne on pg 140}

The full version of this paper, with online appendix,

is available online at www.thepcrj.org

\section{Introduction}

The problem of poor patient adherence to long-term therapy for chronic conditions including asthma and chronic obstructive pulmonary disease (COPD) is well-recognised..$^{1-6}$ By one estimate, adherence to therapy for chronic diseases in developed countries averages $50 \% .^{\prime}$ Of nearly a half million patients in a recent retrospective German study, only $1 \%$ received asthma controller medication in sufficient quantity for the 1 -year study period. ${ }^{3}$ Suboptimal adherence negatively affects patients and their families because of impaired health and quality of life, and costs to healthcare systems accrue because of wasted medications and the expense of poorly controlled disease, manifested in avoidable hospitalisations and emergency care. ${ }^{7-10}$

\footnotetext{
* Corresponding author: Professor David Price, Academic Centre of Primary Care, Division of Applied Health Sciences, University of Aberdeen, Polwarth Building, Foresterhill, Aberdeen AB25 2ZD, UK. Tel: +44 (0)1224 554588 Fax: +44 (0)1224 550683 E-mail: david@rirl.org
} 
Potential barriers to adherence in asthma and COPD include both treatment-related factors - such as difficulties with medication costs, schedule of administration, and inhaler technique - as well as patient-related factors including doubts about the need for therapy, especially when symptoms are absent, or concerns about potential adverse effects. ${ }^{6,11,12}$ Addressing poor adherence therefore requires a multifactorial approach. Recent proposals to improve adherence have focused on promoting a clinician-patient partnership, improving patient education about their illness and therapy, and eliciting and addressing patients' perspectives regarding their care. $^{2,9,13}$

Patient preference is an important factor when choosing an inhaler device for both asthma and COPD..$^{14,15}$ Recent study results suggest that reduced frequency and simplicity of the medication regimen may increase adherence. ${ }^{16,17}$ A better understanding of the characteristics of patients preferring more simple once-daily regimens could be useful for prescribers.

The objective of this study was to identify patient characteristics associated with preference for once-daily controller medication for asthma or COPD by comparing the characteristics of patients who indicated a preference for once-daily therapy with those of patients indicating no preference for once-daily therapy. In addition, we aimed to identify differences between patients with asthma and those with COPD who expressed a preference for a once-daily regimen.

\section{Methods}

\section{Data source and patients}

This was a retrospective observational study using data from the Optimum Patient Care Research Database (OPCRD). Optimum Patient Care provides asthma and COPD review services to approximately 300 general practices distributed across urban and rural areas in England and Scotland. ${ }^{18}$ The OPCRD contains anonymised, longitudinal, research-quality data including routine clinical visit data from electronic patient records and linked patientreported data and outcomes captured via disease-specific questionnaires. Ethics approval for the OPCRD to be used for clinical research was granted by the Trent Research Ethics Committee.

The study questionnaires were included as part of standard clinical assessments and were completed by patients (or the parents of children) with asthma at 81 practices from March 2005 to May 2006 and by patients with COPD at 73 practices from September 2008 to May 2009. For the purposes of this study, data for patients with asthma or COPD were identified by disease coding in practice computer files.

\section{Questionnaires and study endpoints}

We evaluated patient preference for once-daily therapy, disease severity, asthma control or COPD health status, exacerbation history, attitudes and beliefs towards medication, and medication adherence. Patient demographic characteristics were obtained from the research database. The two study questionnaires, specific to either asthma or COPD as appropriate, consisted each of two pages of multiple-choice questions.

The primary study question was similar on the two questionnaires. Patients were asked to choose one of five possible responses (strongly agree, agree, not sure, disagree, strongly disagree) with regard to the following statement of preference for once-daily medication: "I would prefer to take my inhaler/regular COPD treatment once a day".

We categorised asthma severity for each patient according to their recorded medication as either (1) inhaled corticosteroid (ICS) monotherapy (less severe) or (2) ICS plus add-on therapy with longacting $\beta_{2}$-agonist (more severe). The level of control of asthma was assessed with the six-item Asthma Control Questionnaire (ACQ) where a score of $<0.75$ was defined as controlled and a score of $>1.5$ was defined as uncontrolled. ${ }^{19,20}$

We categorised COPD severity using the criteria of the 2004 National Institute for Health and Clinical Excellence (NICE) guidelines based on lung function impairment where a forced expiratory volume in 1 second $\left(\mathrm{FEV}_{1}\right)$ percent predicted of $50-79 \%$ was considered mild, $\mathrm{FEV}_{1}$ of $\mathbf{3 0}-\mathbf{4 9 \%}$ was considered moderate, and $\mathrm{FEV}_{1}<30 \%$ was considered severe. ${ }^{21,22}$ This classification corresponds to current Global Initiative for Chronic Obstructive Lung Disease (GOLD) categories II (moderate COPD), III (severe COPD), and IV (very severe COPD), respectively. ${ }^{23}$ The COPD health status was assessed using two parameters: (1) the Clinical COPD Questionnaire (CCQ), a 10-item self-administered questionnaire with the final score calculated as the mean response to each item scored on a 7-point Likert scale ranging from 0 (asymptomatic/no limitation) to 6 (extremely symptomatic/total limitation);24-26 and (2) the Medical Research Council (MRC) Dyspnoea Score, scored from 1 (not troubled with breathlessness except with strenuous exercise) to 5 (too breathless to leave the house or breathless when dressing or undressing). ${ }^{27,28}$

Exacerbations during the previous year were identified from routine practice data and, for patients with asthma, were defined as an acute course of oral corticosteroids or recorded hospitalisation for asthma. For patients with COPD, exacerbations were defined as an acute course of oral corticosteroids, antibiotics for a lower respiratory tract infection, or a recorded hospitalisation for COPD.

Patients with asthma also completed the Beliefs about Medicines Questionnaire (BMQ). This questionnaire, validated for use in a range of chronic illnesses including asthma, was developed to calculate a medication necessity-concern differential by measuring patients' perceptions of the benefits in relation to the harms of taking a medication. ${ }^{29}$ The 11 -item asthma-specific version can be used to identify patients' doubts about the necessity of taking controller medication and concerns about potential adverse effects. Patients' perceptions of whether their medication is necessary (yes/no/not sure) are captured independent of their opinions of possible medication-related harm. Patients are asked if they agree or disagree, on a 5-point scale, with each of 11 statements. If the patient perceives that the benefits of taking the medication outweigh the costs or concerns, the differential is positive and adherence is predicted to be higher. In contrast, if the patient perceives that the potential harms of taking the medication are greater than the benefits, the differential is negative and adherence is predicted to be low. 
The BMQ is not validated for use in COPD. Instead, patients with COPD answered survey statements about their self-perceived need for, and concerns about, their controller medication with one of five possible responses (strongly agree, agree, not sure, disagree, strongly disagree). The necessity statement was as follows: "I need to take it even when I do not have any breathing symptoms". The concerns statements were as follows: "I sometimes worry about its long-term effects" and "I find it difficult to use".

Self-reported adherence to medication was assessed using the Medication Adherence Report Scale (MARS)..$^{30}$ The MARS for measuring adherence to ICS therapy for asthma consists of five statements answered on a 5-point scale (never, rarely, sometimes, often, and always):

1) I use my preventer inhaler only when I feel breathless.

2) I try to avoid using my preventer inhaler if I can.

3) I forget to take my preventer inhaler.

4) I take less of my preventer inhaler than instructed.

5) I stop taking my preventer inhaler altogether.

Adherence was assessed as low if the patient answered "often" or "always" to any of the questions or as borderline if the patient answered more than one question with "sometimes"; all other responses were defined as good adherence.

The MARS for measuring adherence to COPD therapy consists of four statements, answered on the same 5-point scale and assessed as for asthma:

1) I use [my preventer inhaler] only when I feel breathless.

2) I avoid using it if I can or decide to miss a dose.

3) I forget to take it.

4) I choose to take it once a day.

\section{Statistical analysis}

We tabulated questionnaire results and performed all analyses separately for patients in the asthma and COPD cohorts. Responders and non-responders to the study questionnaires were compared for demographic characteristics and measures of disease severity using the Mann-Whitney $U$ test for age and the $\chi^{2}$ test for categorical variables.

The influence of patient characteristics on their preference for once-daily therapy was evaluated by comparing the percentage of patients who preferred once-daily therapy (agreed or strongly agreed with the once-daily preference statement) with the percentage of patients who did not prefer once-daily therapy (unsure, disagreed, or strongly disagreed) for each questionnaire category. To identify demographic trends in preference, we compared once-daily preference among age groups and between sexes and, to evaluate the influence of severity, we compared once-daily preference between asthma and among COPD disease severities. The once-daily preference according to asthma and COPD disease control measures was analysed by comparing results for an ACQ score of $<0.75$ (controlled asthma) with an ACQ score of >1.5 (uncontrolled); for the CCQ split by median score; and for the MRC Dyspnoea Score dichotomised as $<3$ and $\geq 3$. Once-daily preference among patients with a history of exacerbations was compared with that among patients without a history of exacerbations, separately for each condition.

We evaluated the influence of attitude and beliefs about medication on once-daily preference by comparing the percentages of patients who reported necessity versus no necessity for medication and concerns versus no concerns about their medication. Finally, we compared preference for once-daily medication among patients classified as having good adherence and those with poor adherence according to MARS. Comparisons were made using the $t$ test for continuous variables and the $\chi^{2}$ test for categorical variables.

To further explore patients' preference for once-daily medication, we ran univariate logistic regression models with oncedaily preference as the dependent variable and demographic and

Table 1. Characteristics of patients with asthma or COPD who were responders or non-responders to the study

questionnaires

\begin{tabular}{|c|c|c|c|c|c|c|c|}
\hline \multicolumn{4}{|c|}{ Patients with asthma } & \multicolumn{4}{|c|}{ Patients with COPD } \\
\hline Characteristic & $\begin{array}{l}\text { Responders } \\
n=3,731\end{array}$ & $\begin{array}{l}\text { Non-responders } \\
n=8,652\end{array}$ & p Value* & Characteristic & $\begin{array}{l}\text { Responders } \\
n=2,138\end{array}$ & $\begin{array}{l}\text { Non-responders } \\
n=5,421\end{array}$ & p Value* \\
\hline Sex, female & $2,174(58.3)$ & $4,776(55.2)$ & 0.001 & Sex, female & $980(45.8)$ & $2,877(53.1)$ & $<0.001$ \\
\hline Age, mean (SD) & $45.6(15.0)$ & $40.3(17.1)$ & $<0.001$ & Age, mean (SD) & $70.4(9.8)$ & $68.9(11.5)$ & $<0.001$ \\
\hline Exacerbations & & & & Exacerbations & & & \\
\hline 0 & $3,628(97.2)$ & $7,498(86.7)$ & $<0.001$ & 0 & $768(35.9)$ & $3,085(56.9)$ & $<0.001$ \\
\hline 1 & $71(1.9)$ & $702(8.1)$ & & 1 & $318(14.9)$ & $968(17.9)$ & \\
\hline$\geq 2$ & $32(0.9)$ & $452(5.2)$ & & $\geq 2$ & $1,052(49.2)$ & $1,368(25.2)$ & \\
\hline SABA prescriptions & & & & COPD severity & & & \\
\hline 0 & $670(18.0)$ & $1,894(21.9)$ & $<0.001$ & Mild & $806(37.7)$ & $2,212(40.8)$ & $<0.001$ \\
\hline $1-2$ & $1,382(37.0)$ & $2,764(31.9)$ & & Moderate & $405(18.9)$ & $882(16.3)$ & \\
\hline $3-5$ & $859(23.0)$ & $1,529(17.7)$ & & Severe & $81(3.8)$ & 195 (3.6) & \\
\hline$\geq 6$ & $820(22.0)$ & $2,465(28.5)$ & & Unknown & $846(39.6)$ & $2,132(39.3)$ & \\
\hline
\end{tabular}

*Mann-Whitney $U$ test for age comparison; other comparisons made using the $\chi^{2}$ test. Values are $\mathrm{n}$ (\%) unless otherwise stated.

$\mathrm{COPD}=$ chronic obstructive pulmonary disease, $\mathrm{SABA}=$ short-acting $\beta 2$-agonist. 
clinical characteristics as explanatory variables. Those that were individually significant at the $5 \%$ level were included in a multivariate model.

Analyses were performed using IBM SPSS Statistics Versions 16 and 20.

\section{Results}

Questionnaires were returned by $30 \%$ of patients with asthma and $42 \%$ of patients with COPD. There were several statistically significant differences between responders and non-responders to the study questionnaire (Table 1). Among patients with asthma, responders were more likely to be female and older and to have no exacerbations during the baseline year while, among patients with COPD, responders were more likely to be male and older and to have had two or more exacerbations during the baseline year.

All 3,731 patients with asthma who returned the survey completed the question about once-daily preference and were included in the study. The age range of these patients was 2-94 years (mean age 45.6 years) and 2,174 (58.3\%) were women. Of the 2,138 patients with COPD who returned the survey and completed the once-daily preference question, the age range was 35-98 years (mean age 70.4 years) and 980 (45.8\%) were women.

\section{Patients who indicated a preference for once-daily} medication

The percentage of patients who indicated that they preferred oncedaily medication was similar in the asthma and COPD cohorts (Figure 1). Of the 3,731 patients with asthma, 1,801 (48.2\%) preferred a once-daily regimen (strongly agree or agree), 1,011 (27.1\%) were not sure, and 919 (24.7\%) did not prefer once-daily (disagree or strongly disagree). Of the 2,138 patients with COPD, 955 (44.7\%) preferred a once-daily schedule, 533 (24.9\%) were not sure, and 650 (30.4\%) did not prefer once-daily therapy.

There was no significant difference between the mean age or sex of patients who indicated a preference for once-daily inhaler medication and those who indicated uncertainty or disagreed (Table 2). The percentages of male and female patients who

Figure 1. Patients' level of agreement with a statement indicating preference for once-daily therapy

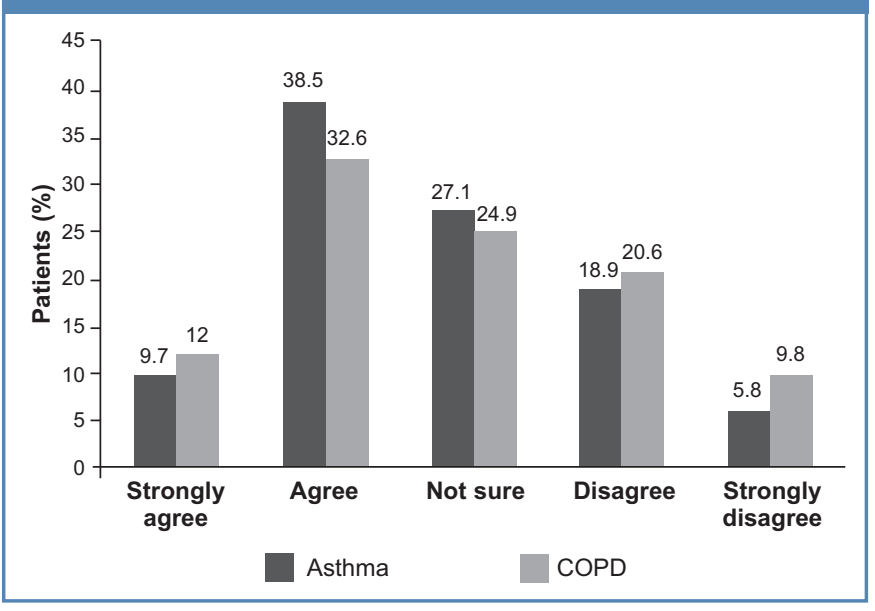

PRIMARY CARE RESPIRATORY JOURNAL www.thepcrj.org preferred once-daily therapy were similar within the two cohorts (Table 2).

Preference for once-daily therapy did not appear to be influenced by severity of disease either for asthma or COPD (Table 2). However, for patients with asthma, there was a significant difference by disease control as a greater proportion of patients with better asthma control (ACQ score <0.75) indicated a preference for once-daily therapy compared with those who had poorer asthma control (ACQ score >1.5). For patients with COPD, the level of disease control did not significantly influence preference for once-daily therapy.

The history of exacerbations during the previous year did not significantly influence the preference for once-daily therapy among patients with either asthma or COPD (Table 2).

Patients' beliefs about the necessity for their controller medication significantly influenced preference for once-daily therapy, but in opposite directions in the two cohorts. In the asthma cohort, a greater proportion of patients who reported low compared with high necessity for controller medication indicated a preference for once-daily therapy (Table 2). In contrast, in the COPD cohort, a greater proportion of patients reporting high compared with low necessity for their regular medication preferred once-daily therapy.

Significantly more patients in both cohorts who expressed concerns about regular medication also preferred once-daily therapy (Table 2). The results were also similar for the asthma and COPD cohorts with regard to adherence to therapy as indicated by the MARS, with a significantly greater proportion of patients with lower MARS adherence indicating a preference for once-daily therapy than those with good adherence (Table 2).

The results of univariate logistic regression analyses with oncedaily preference as the dependent variable supported those of the bivariate comparisons (see Table 3). The results of the multivariate model provided further support and additional detail regarding patient preferences (Table 4). For patients with asthma, the odds of preferring once-daily therapy were significantly greater in patients with borderline or low adherence than in those with good adherence. For patients with COPD, significant differences in the odds of once-daily preference were evident only between patients with good versus low adherence (Table 4). In addition, patients with medication concerns, as well as those who were not sure, had significantly greater odds of preferring once-daily medication for COPD than did patients with no concerns.

\section{Disaussion}

\section{Main findings}

We found that patients with asthma or COPD who reported concerns about their controller medication were more likely to prefer oncedaily therapy than those with low or no medication concerns. Moreover, in both the asthma and COPD cohorts, patients reporting poor medication adherence were more likely than those with good adherence to prefer once-daily therapy. There was no significant relationship between once-daily preference and age, sex, disease severity, or exacerbation history in either cohort. However, the results 
Table 2. Characteristics of patients with asthma or COPD who preferred once-daily therapy

\begin{tabular}{|c|c|c|c|c|c|}
\hline \multicolumn{3}{|c|}{ Patients with asthma $(n=3,731)$} & \multicolumn{3}{|c|}{ Patients with COPD $(n=2,138)$} \\
\hline Characteristic & $\begin{array}{l}\text { Preference for once- } \\
\text { daily therapy }\end{array}$ & No preference & Characteristic & $\begin{array}{l}\text { Preference for once- } \\
\text { daily therapy }\end{array}$ & No preference \\
\hline Sex, female $(n=2,174)$ & $1054(48.5)$ & $1120(51.5)$ & Sex, female $(n=980)$ & $430(43.9)$ & $550(56.1)$ \\
\hline Sex, male $(n=1,550)$ & $743(47.9)$ & $807(52.1)$ & Sex, male $(n=1,158)$ & $525(45.3)$ & $633(54.7)$ \\
\hline Age, mean (SD) & $45.8(14.3)$ & $45.6(15.6)$ & Age, mean (SD) & $70.4(9.8)$ & $70.2(9.8)$ \\
\hline \multicolumn{6}{|c|}{ Disease severity $^{\dagger}$} \\
\hline $\operatorname{Rx} \operatorname{ICS}(n=2,753)$ & $1,334(48.4)$ & $1,419(51.5)$ & Mild $(n=806)$ & $368(45.7)$ & $438(54.3)$ \\
\hline $\mathrm{Rx} I C S+\operatorname{LABA}(n=926)^{\ddagger}$ & $436(47.1)$ & $490(52.9)$ & Moderate $(n=405)$ & $182(44.9)$ & $223(55.1)$ \\
\hline- & - & - & Severe $(n=81)^{\ddagger}$ & $32(39.5)$ & $49(60.5)$ \\
\hline \multicolumn{6}{|c|}{ Disease control $^{\dagger}$} \\
\hline $\begin{array}{l}\text { ACQ score }<0.75 \\
(n=2,016)\end{array}$ & $1,026(50.9)$ & $990(49.1)^{*}$ & $\begin{array}{l}\text { CCQ score } 0-2.2 \\
(n=1094)\end{array}$ & $469(42.9)$ & $625(57.1)$ \\
\hline $\begin{array}{l}\text { ACQ score }>1.5 \\
(n=1,295)^{\ddagger}\end{array}$ & $605(46.7)$ & $690(53.3)$ & $\begin{array}{l}\text { CCQ score }>2.2 \\
(n=1044)\end{array}$ & $486(46.6)$ & $558(53.4)$ \\
\hline- & - & - & $\begin{array}{l}\text { MRC Dyspnoea <3 } \\
(n=990)\end{array}$ & $427(43.1)$ & $563(56.9)$ \\
\hline- & - & - & $\begin{array}{l}\text { MRC Dyspnoea } \geq 3 \\
(n=1117)^{\ddagger}\end{array}$ & $515(46.1)$ & $602(53.9)$ \\
\hline \multicolumn{6}{|c|}{ Exacerbation history for previous year ${ }^{\dagger}$} \\
\hline $\begin{array}{l}\text { No exacerbation } \\
(n=3,628)\end{array}$ & $1,749(48.2)$ & $1,879(51.8)$ & $\begin{array}{l}\text { No exacerbation } \\
(\mathrm{n}=768)\end{array}$ & $342(44.5)$ & $426(55.5)$ \\
\hline $\begin{array}{l}\geq 1 \text { exacerbation } \\
(n=103)\end{array}$ & $52(50.5)$ & $51(49.5)$ & $\begin{array}{l}\geq 1 \text { exacerbation } \\
(n=1370)\end{array}$ & $613(44.7)$ & $757(55.3)$ \\
\hline \multicolumn{6}{|c|}{ Beliefs about necessity for and concerns regarding controller medication ${ }^{\dagger}$} \\
\hline $\begin{array}{l}\text { Necessity 'yes' } \\
(n=1,174)\end{array}$ & $482(41.1)$ & $692(58.9)^{* *}$ & $\begin{array}{l}\text { Necessity 'yes' } \\
(n=1202)\end{array}$ & $549(45.7)$ & $653(54.3)^{\star}$ \\
\hline $\begin{array}{l}\text { Necessity 'no' } \\
(n=2,557)\end{array}$ & $1,319(51.6)$ & $1,238(48.4)$ & $\begin{array}{l}\text { Necessity 'no' } \\
(n=522)\end{array}$ & $199(38.1)$ & $323(61.9)$ \\
\hline- & - & - & $\begin{array}{l}\text { Necessity 'not sure' } \\
(n=321)^{\ddagger}\end{array}$ & $149(46.4)$ & $172(53.6)$ \\
\hline $\begin{array}{l}\text { Concerns 'yes' } \\
(n=2,148)\end{array}$ & $1,199(55.8)$ & $949(44.2)^{* *}$ & $\begin{array}{l}\text { Concerns 'yes' } \\
(n=824)\end{array}$ & $431(52.3)$ & $393(47.7)^{* *}$ \\
\hline \multirow[t]{2}{*}{$\begin{array}{l}\text { Concerns 'no' } \\
(n=1,583)\end{array}$} & $602(38.0)$ & $981(62.0)$ & $\begin{array}{l}\text { Concerns 'no' } \\
(n=643)\end{array}$ & $209(32.5)$ & $434(67.5)$ \\
\hline & - & - & $\begin{array}{l}\text { Concerns 'not sure' } \\
(\mathrm{n}=571)^{\ddagger}\end{array}$ & $251(44.0)$ & $320(56.0)$ \\
\hline \multicolumn{6}{|c|}{ Medication adherence based on Medication Adherence Rating Scale (MARS) ${ }^{\dagger}$} \\
\hline Good $(n=1,403)$ & $632(45.0)$ & $771(55.0)^{*}$ & Good $(n=485)$ & $129(26.6)$ & $356(73.4)^{* *}$ \\
\hline Borderline $(n=479)$ & $260(54.3)$ & $219(45.7)$ & Borderline $(n=134)$ & $60(44.8)$ & $74(55.2)$ \\
\hline Low $(n=1,849)$ & $909(49.2)$ & $940(50.8)$ & Low $(n=1478)^{\ddagger}$ & 753 (50.9) & $725(49.1)$ \\
\hline
\end{tabular}

${ }^{*} \mathrm{p}<0.05,{ }^{*} \mathrm{p}<0.001$ (t test for continuous variables [age] and $\chi^{2}$ test for categorical variables) between patients with preference for once-daily medication vs. those unsure or not preferring once-daily.

tSee text for definitions.

\#Patient data were missing for the following categories: asthma disease severity ( $n=52)$; ACQ score $(n=420)$; COPD disease severity $(n=846)$; MRC dyspnoea score $(n=31)$; COPD necessity ( $n=93)$; COPD concerns ( $n=100)$; COPD adherence $(n=41)$.

$\mathrm{ACQ}=$ Asthma Control Questionnaire, $C \mathrm{CQ}=C$ linical $C O P D$ Questionnaire, COPD=chronic obstructive pulmonary disease, ICS=inhaled corticosteroids, $\angle A B A=$ long-acting $\beta_{2}$-agonist, MRC=Medical Research Council.

differed for the asthma and COPD cohorts with regard to selfperceived need for therapy - namely, preference for once-daily therapy was more common among patients with asthma who reported a low need for therapy and, conversely, among patients with
COPD who reported a high need for therapy. Moreover, asthma patients with good disease control were more likely to prefer the once-daily schedule, whereas disease control was not a significant factor among COPD patients. 


$\begin{aligned} & \text { Table 3. Influence of patient characteristics on their } \\
& \text { preference for once-daily therapy: summary for patients } \\
& \text { with asthma or COPD }\end{aligned}$
\begin{tabular}{lll} 
Characteristic & $\begin{array}{l}\text { Preference for } \\
\text { once-daily in } \\
\text { asthma }\end{array}$ & $\begin{array}{l}\text { Preference for } \\
\text { once-daily in } \\
\text { COPD }\end{array}$ \\
\hline Age & X & X \\
\hline Sex & X & X \\
\hline Disease severity & $X$ & X \\
\hline Disease control & $\checkmark$ (well controlled) & X \\
\hline Exacerbation history & $X$ & X \\
\hline Self-perceived & $\checkmark$ & $\checkmark$ \\
medication need & (low necessity) & (high necessity) \\
\hline Medication concerns & $\checkmark$ (concerned & $\checkmark$ (concerned \\
& patients) & patients) \\
\hline Adherence & $\checkmark$ (poor adherers) & $\checkmark$ (poor adherers) \\
\hline X=no influence, $\checkmark=$ statistically significant influence.
\end{tabular}

\section{Strengths and limitations of this study}

The strengths of this study include the large patient population, drawn from primary care where most patients with asthma and COPD are managed. Study results are based on patient selfcompleted questionnaires, which is important in evaluating the patient perspective. ${ }^{31}$ A study limitation is the fact that, although the study sample was large, the response rate to the survey was low
(30\% for asthma and 42\% for COPD), and there were several significant differences between patients who responded and those who did not respond to the study questionnaires. Among patients with asthma, responders tended to be older and to have better asthma control, as indicated by fewer exacerbations and fewer prescriptions for short-acting $\beta_{2}$-agonists in the previous year. Among patients with COPD, the age difference between responders and non-responders was small, but responders were more likely to be male and to have experienced two or more exacerbations in the previous year.

Another study limitation is that we did not analyse results according to whether patients were already receiving once-daily therapy; this would have been of interest. Whereas few asthma therapies are administered once daily, several COPD therapies are. For patients who were already prescribed once-daily therapy, expressing a once-daily 'preference' could perhaps be interpreted instead as 'satisfaction'. When classifying adherence, we categorised patients who indicated complete ('always') or nearcomplete ('often') agreement with at least one question indicative of suboptimal adherence as 'low adherers'. We recognise that this pragmatic approach may have overestimated the level of adherence (categorised as 'good') of patients who indicated partial ('sometimes') agreement to more than one of the statements relating to suboptimal adherence. Furthermore, it would have been of interest to examine whether once-daily preference independently relates to reported adherence after removing the effects of beliefs (necessity and concerns).

Table 4. Patient and clinical characteristics predictive of a preference for once-daily medication: multivariate model

\begin{tabular}{|c|c|c|}
\hline Category & Odds ratio $(95 \% \mathrm{Cl})$ & $\mathrm{p}$ Value \\
\hline \multicolumn{3}{|l|}{ Patients with asthma $(n=3,731)$} \\
\hline Asthma control status: Controlled & 1.00 & - \\
\hline Self-perceived medication necessity: No & 1.00 & - \\
\hline vs. Self-perceived medication necessity: Yes & 0.64 (0.54 to 0.75$)$ & $<0.001$ \\
\hline Medication concerns: No & 1.00 & - \\
\hline Adherence: Good & 1.00 & - \\
\hline vs. Borderline & 1.55 (1.24 to 1.94$)$ & $<0.001$ \\
\hline vs. Low & $1.45(1.23$ to 1.71$)$ & $<0.001$ \\
\hline \multicolumn{3}{|l|}{ Patients with COPD $(n=2,138)$} \\
\hline Self-perceived medication necessity: No & 1.00 & - \\
\hline vs. Medication concerns: Not sure & $1.42(1.11$ to 1.82$)$ & 0.006 \\
\hline vs. Medication concerns: Yes & $1.99(1.58$ to 2.50$)$ & $<0.001$ \\
\hline Adherence: Low & 1.00 & - \\
\hline vs. Borderline & $0.78(0.54$ to 1.13$)$ & 0.192 \\
\hline vs. Good & $0.38(0.30$ to 0.49$)$ & $<0.001$ \\
\hline
\end{tabular}




\section{Interpretation of findings in relation to previously published work}

The study findings suggest that there are differences between people with asthma and those with COPD and, moreover, that inherent differences in the nature of asthma and COPD may influence patient perceptions and behaviour regarding prescribed therapy. Asthma symptoms are episodic, and patients can experience prolonged symptom-free periods. On the other hand, COPD symptoms are progressive and often debilitating, and affected patients tend to have multiple co-morbidities which may mean they are already on a complex cocktail of drugs and are keen to simplify their treatment regimen where possible. Effective controller and reliever therapies are available for asthma, but COPD treatment options are palliative and cannot fully prevent or relieve symptoms. Asthma is rarely fatal while COPD often is.

However, both asthma and COPD share the challenge for patients of maintaining adherence to regular long-term controller therapy, typically delivered by inhalation. A simple treatment regimen, preferably once daily, would seem desirable for both asthma and COPD. Half of the patients in this study indicated a once-daily preference, with a further quarter unsure of their preference. Patients who were unsure may not have been aware of the full range of treatment options and may have worried that oncedaily therapy would be less effective. This possibility highlights the need for physicians to communicate and educate their patients and, furthermore, to make tailored individualised treatment prescriptions.

There are few previous studies of adherence as it relates to treatment frequency in respiratory disease. A recent review found only four studies of asthma or COPD from 1998 to 2007 that examined this relationship. ${ }^{32}$ These studies provided inconsistent support for the use of a once-daily regimen for promoting adherence, although the results did suggest that complex regimens may be associated with lower adherence. There is robust evidence, however, from the study of other chronic diseases, such as HIV/AIDS and diabetes, that reducing dose frequency improves adherence. ${ }^{32}$ More recently, Price and coworkers ${ }^{17}$ reported significantly better adherence to once-daily compared with twice-daily administration of mometasone furoate by dry powder inhaler in a large open-label study enrolling 1,200 patients with asthma.

\section{Implications for future research, policy and practice}

Our findings suggest that an understanding of patients' beliefs about their treatment - in particular their self-perceived necessity and concerns about therapy - can be a means to understanding their treatment preferences and potentially to improve their adherence to controller therapy. In previous studies of asthma and COPD, the beliefs of patients or parents of patients correlated with medication adherence. ${ }^{33-36}$ Menckeberg and coworkers ${ }^{34}$ found that patients' beliefs about ICS (necessity and concerns) predicted their refill adherence to ICS. Similarly, in a study of 261 urban patients with asthma, the odds of adherence increased for those who felt that using ICS when asymptomatic was important and for those who were confident in using ICS; conversely, adherence was decreased by worries about side-effects or feeling the regimen was hard to follow. ${ }^{35}$ In an earlier study of patients with asthma or COPD, van
Grunsven et al. ${ }^{36}$ reported that patients' conviction of the importance of treatment was a significant positive influence on adherence.

\section{Conclusions}

In both asthma and COPD, preference for once-daily controller medication was significantly associated with poor adherence and with patient concerns about their medication. In asthma, good control and low self-perceived controller medication need was associated with once-daily preference. By contrast, in COPD, a high self-perceived need for controller medication was associated with a preference for once-daily therapy. The results of this study corroborate those of other studies indicating that decisions about therapy should be made in consultation with patients and tailored to their individual needs and preferences.

\section{Handling editor Maureen George Statistical review Gopal Netuveli}

Acknowledgements We thank Annie Burden for her help with statistical analyses and Rob Horne for his input on the study design and analyses.

Conflicts of interest DP has consultant arrangements with Almirral, AstraZeneca, Boehringer Ingelheim, Chiesi, GlaxoSmithKline, Merck, Mundipharma, Medapharma, Novartis, Napp, Nycomed, Pfizer, Sandoz, and Teva. He or his research team have received grants and support for research in respiratory disease from the following organisations in the last 5 years: UK National Health Service, Aerocrine, AstraZeneca, Boehringer Ingelheim, Chiesi, GlaxoSmithKline, Merck, Mundipharma, Novartis, Nycomed, Orion, Pfizer, and Teva. He has spoken for Almirral, AstraZeneca, Activaero, Boehringer Ingelheim, Chiesi, Cipla, GlaxoSmithKline, Kyorin, Novartis, Merck, Mundipharma, Pfizer, and Teva. He has shares in AKL Ltd which produces phytopharmaceuticals. He is the sole owner of Research in Real Life Ltd and its subsidiary social enterprise Optimum Patient Care. AJL receives ad hoc payment for statistical consultancy with RIRL. EJS and JVZ are employees of RiRL. EVH is a consultant to RiRL and has done freelance writing work for Merck, Aerocrine, and TevaFrance. At the time this study was conducted, LK and AC were employees of RiRL and AW was an employee of GSK R\&D.

Contributorship DP, EJS, and AW conceived and designed the study. LK conducted the analyses, with help from JVZ and AJL. EVH wrote the initial draft of the paper. All authors contributed to the interpretation of the data, writing of the manuscript, and review of the final draft. DP is the study guarantor.

Funding The study was sponsored by GlaxoSmithKline. The funders had no role in the conduct of the study or interpretation of study results.

\section{References}

1. World Health Organization. Adherence to long-term therapies: evidence for action. Geneva: World Health Organization, 2003.

2. Cutler DM, Everett W. Thinking outside the pillbox-medication adherence as a priority for health care reform. N Engl J Med 2010;362(17):1553-5. http://dx.doi.org/10.1056/NEJMp1002305

3. Hasford J, Uricher J, Tauscher M, Bramlage P, Virchow JC. Persistence with asthma treatment is low in Germany especially for controller medication: a population based study of 483,051 patients. Allergy 2010;65(3):347-54. http://dx.doi.org/10.1111/j.1398-9995.2009.02161.x

4. Cochrane MG, Bala MV, Downs KE, Mauskopf J, Ben-Joseph RH. Inhaled corticosteroids for asthma therapy: patient compliance, devices, and inhalation technique. Chest 2000;117(2):542-50. http://dx.doi.org/10.1378/chest.117.2.542

5. Bourbeau J, Bartlett SJ. Patient adherence in COPD. Thorax 2008;63(9):831-8. http://dx.doi.org/10.1136/thx.2007.086041

6. Charles MS, Blanchette CM, Silver H, Lavallee D, Dalal AA, Mapel D. Adherence to controller therapy for chronic obstructive pulmonary disease: a review. Curr Med Res Opin 2010;26(10):2421-9. http://dx.doi.org/10.1185/03007995.2010.516284

7. Barnes PJ, Jonsson B, Klim JB. The costs of asthma. Eur Respir J 1996;9(4):636-42. http://dx.doi.org/10.1183/09031936.96.09040636

8. Bahadori K, Doyle-Waters MM, Marra C, et al. Economic burden of asthma: a systematic review. BMC Pulm Med 2009;9:24.

http://dx.doi.org/10.1186/1471-2466-9-24 
9. George J, Kong DC, Thoman R, Stewart K. Factors associated with medication nonadherence in patients with COPD. Chest 2005;128(5):3198-204. http://dx.doi.org/10.1378/chest.128.5.3198

10. Dalal AA, Shah M, D'Souza AO, Rane P. Costs of COPD exacerbations in the emergency department and inpatient setting. Respir Med 2011;105(3):454-60. http://dx.doi.org/10.1016/j.rmed.2010.09.003

11. Haughney J, Price D, Kaplan A, et al. Achieving asthma control in practice: understanding the reasons for poor control. Respir Med 2008;102(12):1681-93. http://dx.doi.org/10.1016/j.rmed.2008.08.003

12. Horne R. Compliance, adherence, and concordance: implications for asthma treatment. Chest 2006;130(1 Suppl):65S-72S. http://dx.doi.org/10.1378/chest.130.1_suppl.65S

13. Horne R, Price D, Cleland J, et al. Can asthma control be improved by understanding the patient's perspective? BMC Pulm Med 2007;7:8. http://dx.doi.org/10.1186/1471-2466-7-8

14. Papi A, Haughney J, Virchow JC, Roche N, Palkonen S, Price D. Inhaler devices for asthma: a call for action in a neglected field. Eur Respir J 2011;37(5):982-5. http://dx.doi.org/10.1183/09031936.00150910

15. Vincken W, Dekhuijzen PR, Barnes P. The ADMIT series - Issues in inhalation therapy. 4) How to choose inhaler devices for the treatment of COPD. Prim Care Respir $J$ 2010;19(1):10-20. http://dx.doi.org/10.4104/pcri.2009.00062

16. Price $D$, Musgrave SD, Shepstone $L$, et al. Leukotriene antagonists as first-line or addon asthma-controller therapy. N Engl J Med 2011;364(18):1695-707. http://dx.doi.org/10.1056/NEJMoa1010846

17. Price D, Robertson A, Bullen K, Rand C, Horne R, Staudinger H. Improved adherence with once-daily versus twice-daily dosing of mometasone furoate administered via a dry powder inhaler: a randomized open-label study. BMC Pulm Med 2010;10:1. http://dx.doi.org/10.1186/1471-2466-10-1

18. Optimum Patient Care. http://www.optimumpatientcare.org/ (accessed August 2012)

19. Juniper EF, Svensson K, Mork AC, Stahl E. Measurement properties and interpretation of three shortened versions of the asthma control questionnaire. Respir Med 2005;99(5):553-8. http://dx.doi.org/10.1016/j.rmed.2004.10.008

20. Juniper EF, Bousquet J, Abetz L, Bateman ED. Identifying 'well-controlled' and 'not well-controlled' asthma using the Asthma Control Questionnaire. Respir Med 2006;100(4):616-21. http://dx.doi.org/10.1016/j.rmed.2005.08.012

21. National Clinical Guideline Centre. Chronic obstructive pulmonary disease: management of chronic obstructive pulmonary disease in adults in primary and secondary care. CG101. London: National Clinical Guideline Centre, 2010. http://guidance.nice.org.uk/CG101/Guidance/pdf/English (accessed August 2012).

22. National Clinical Guideline Centre. Chronic obstructive pulmonary disease: management of chronic obstructive pulmonary disease in adults in primary and secondary care. CG12. London: National Clinical Guideline Centre, 2004. http://guidance.nice.org.uk/CG12 (accessed August 2012).

23. Global Initiative for Chronic Obstructive Pulmonary Disease (GOLD). Global Strategy for Diagnosis, Management, and Prevention of COPD. http://www.goldcopd.org/ (accessed August 2012)

24. Clinical COPD Questionnaire. http://www.ccq.nl/ (accessed August 2012).

25. Jones PW, Price D, van der Molen T. Role of clinical questionnaires in optimizing everyday care of chronic obstructive pulmonary disease. Int J Chron Obstruct Pulmon Dis 2011;6:289-96. http://dx.doi.org/10.2147/COPD.S18181

26. van der Molen T, Willemse BW, Schokker S, ten Hacken NH, Postma DS, Juniper EF Development, validity and responsiveness of the Clinical COPD Questionnaire. Health Qual Life Outcomes 2003;1:13. http://dx.doi.org/10.1186/1477-7525-1-13

27. Fletcher CM, Elmes PC, Fairbairn AS, Wood $\mathrm{CH}$. The significance of respiratory symptoms and the diagnosis of chronic bronchitis in a working population. $\mathrm{Br}$ Med J 1959;2(5147):257-66. http://dx.doi.org/10.1136/bmj.2.5147.257

28. Stenton C. The MRC breathlessness scale. Occup Med (Lond) 2008;58(3):226-7. http://dx.doi.org/10.1093/occmed/kgm162

29. Horne R, Weinman J, Hankins M. The Beliefs about Medicines Questionnaire: the development and evaluation of a new method for assessing the cognitive representation of medication. Psychol Health 1999;14(1):1-24. http://dx.doi.org/10.1080/08870449908407311

30. Horne R, Weinman J. Self-regulation and self-management in asthma: exploring the role of illness perceptions and treatment beliefs in explaining non-adherence to preventer medication. Psychol Health 2002;17(1):17-32 http://dx.doi.org/10.1080/08870440290001502

31. Clatworthy J, Price D, Ryan D, Haughney J, Horne R. The value of self-report assessment of adherence, rhinitis and smoking in relation to asthma control. Prim Care Respir J 2009;18(4):300-5. http://dx.doi.org/10.4104/pcrj.2009.00037

32. Ingersoll KS, Cohen J. The impact of medication regimen factors on adherence to chronic treatment: a review of literature. J Behav Med 2008;31(3):213-24. http://dx.doi.org/10.1007/s10865-007-9147-y

33. Conn KM, Halterman JS, Lynch K, Cabana MD. The impact of parents' medication beliefs on asthma management. Pediatrics 2007;120(3):e521-6. http://dx.doi.org/10.1542/peds.2006-3023

34. Menckeberg TT, Bouvy ML, Bracke $M$, et al. Beliefs about medicines predict refill adherence to inhaled corticosteroids. J Psychosom Res 2008;64(1):47-54 http://dx.doi.org/10.1016/j.jpsychores.2007.07.016

35. Ponieman D, Wisnivesky JP, Leventhal H, Musumeci-Szabo TJ, Halm EA. Impact of positive and negative beliefs about inhaled corticosteroids on adherence in inner-city asthmatic patients. Ann Allergy Asthma Immunol 2009;103(1):38-42. http://dx.doi.org/10.1016/S1081-1206(10)60141-X

36. van Grunsven PM, van Schayck $C P$, van Deuveren $M$, van Herwaarden $C L$, Akkermans RP, van Weel C. Compliance during long-term treatment with fluticasone propionate in subjects with early signs of asthma or chronic obstructive pulmonary disease (COPD): results of the Detection, Intervention, and Monitoring Program of COPD and Asthma (DIMCA) Study. J Asthma 2000;37(3):225-34. http://dx.doi.org/10.3109/02770900009055445

\section{Available online at http://www.thepcrj.org}


Appendix. STROBE Statement-Checklist for cohort studies - Price D, et al. Characteristics of patients preferring once-daily controller therapy for asthma and chronic obstructive pulmonary disease: retrospective observational study

\begin{tabular}{|c|c|c|c|}
\hline & $\begin{array}{l}\text { Hem } \\
\text { iNo }\end{array}$ & Pagejto. & Recomanetdiatiou \\
\hline \multirow[t]{2}{*}{ Fifle atil abstradt } & 1 & $\sqrt{1}$ & 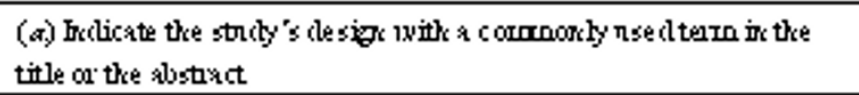 \\
\hline & & $\sqrt{1}$ & 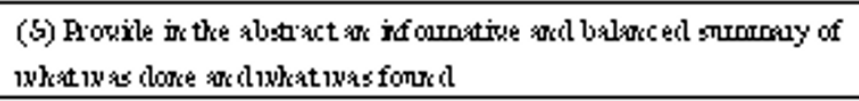 \\
\hline \multicolumn{4}{|l|}{ Ghroductiou } \\
\hline Backgorudlatiorale & 2 & $\sqrt{1-2}$ & 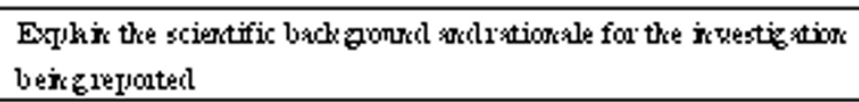 \\
\hline Objectives & 3 & $\sqrt{2}$ & 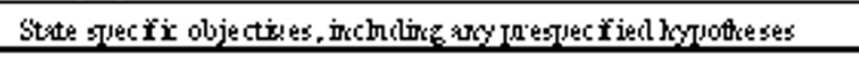 \\
\hline \multicolumn{4}{|l|}{ hletloods } \\
\hline Sorly desizic & 4 & $\sqrt{2}$ & 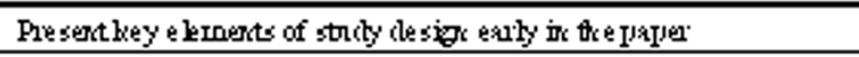 \\
\hline Setting & $S$ & $\sqrt{2}$ & 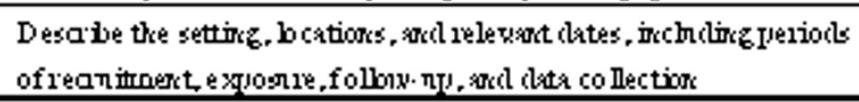 \\
\hline \multirow[t]{2}{*}{ Patirinjacts } & 6 & $\sqrt{2}$ & 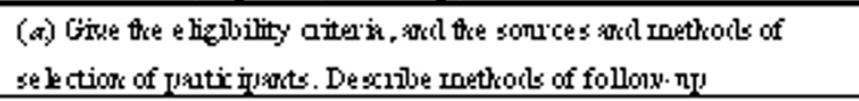 \\
\hline & & $\mathrm{n} / \mathrm{a}$ & 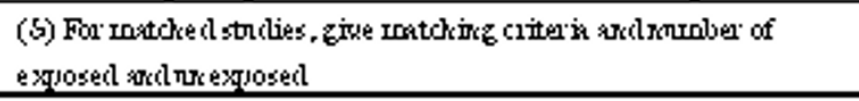 \\
\hline Varibles & 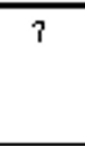 & $\sqrt{2-3}$ & 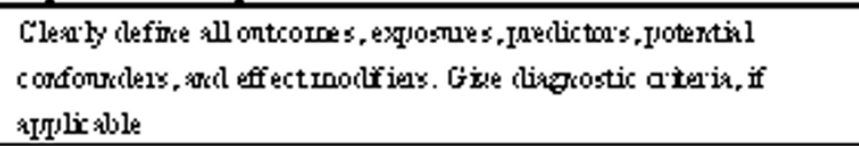 \\
\hline $\begin{array}{l}\text { Data sonucesi } \\
\text { Inestureinest }\end{array}$ & $8: k$ & $\sqrt{2-3}$ & 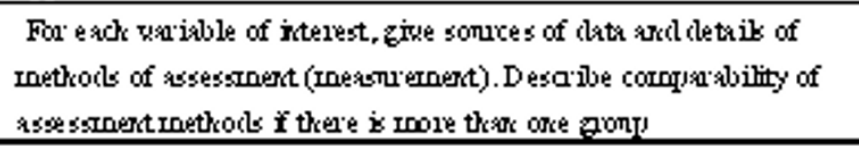 \\
\hline Bixs & 9 & $\sqrt{3-4}$ & Desalve ary effouts to adke $x$ jotential somuces of bias \\
\hline Sorcly sime & 10 & $\sqrt{2-3}$ & ExIlain kow the strcly sixe ly as aried at \\
\hline Quactiatide valables & 11 & $\sqrt{2-3}$ & 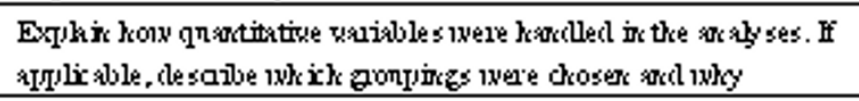 \\
\hline \multirow[t]{5}{*}{ Stuistixlmethols } & 12 & $\sqrt{3-4}$ & 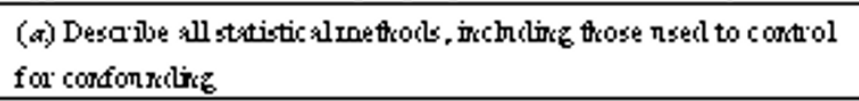 \\
\hline & & $\sqrt{3-4}$ & $\begin{array}{l}\text { (5) Desaibe soy roe thodk nsed to exarnice snbaronIs and } \\
\text { interactions }\end{array}$ \\
\hline & & $\mathrm{n} / \mathrm{a}$ & 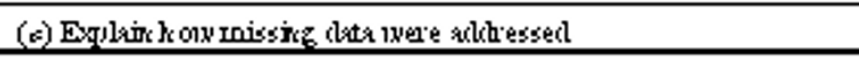 \\
\hline & & $\mathrm{n} / \mathrm{a}$ & 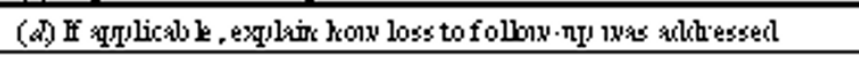 \\
\hline & & $\mathrm{n} / \mathrm{a}$ & (a) Desalue any sersitioty analyses \\
\hline Reults & & $\sqrt{4}$ & \\
\hline \multirow[t]{3}{*}{ Patirinsats } & $13: k$ & $\sqrt{4}$ & 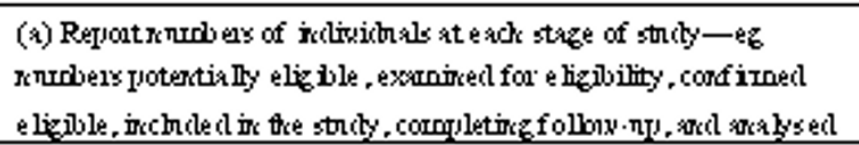 \\
\hline & & $\sqrt{4}$ & (b) Gine reasons for rook Janticination at eack stage \\
\hline & & $\sqrt{ }$ & (c) Concsiler $\pi$ se of a flon diagurn \\
\hline \multirow[t]{2}{*}{ Desaritutive data } & $14: k$ & $\sqrt{3-5}$ & 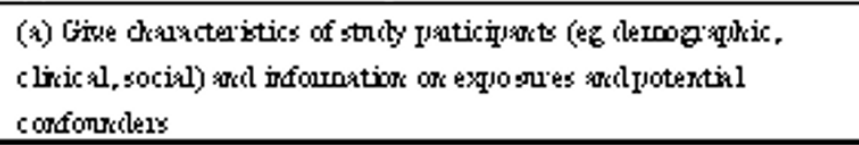 \\
\hline & & $\sqrt{5}$ & 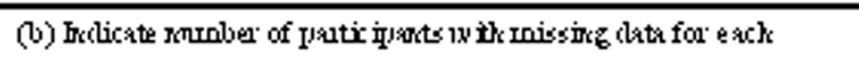 \\
\hline
\end{tabular}


valiale of interest

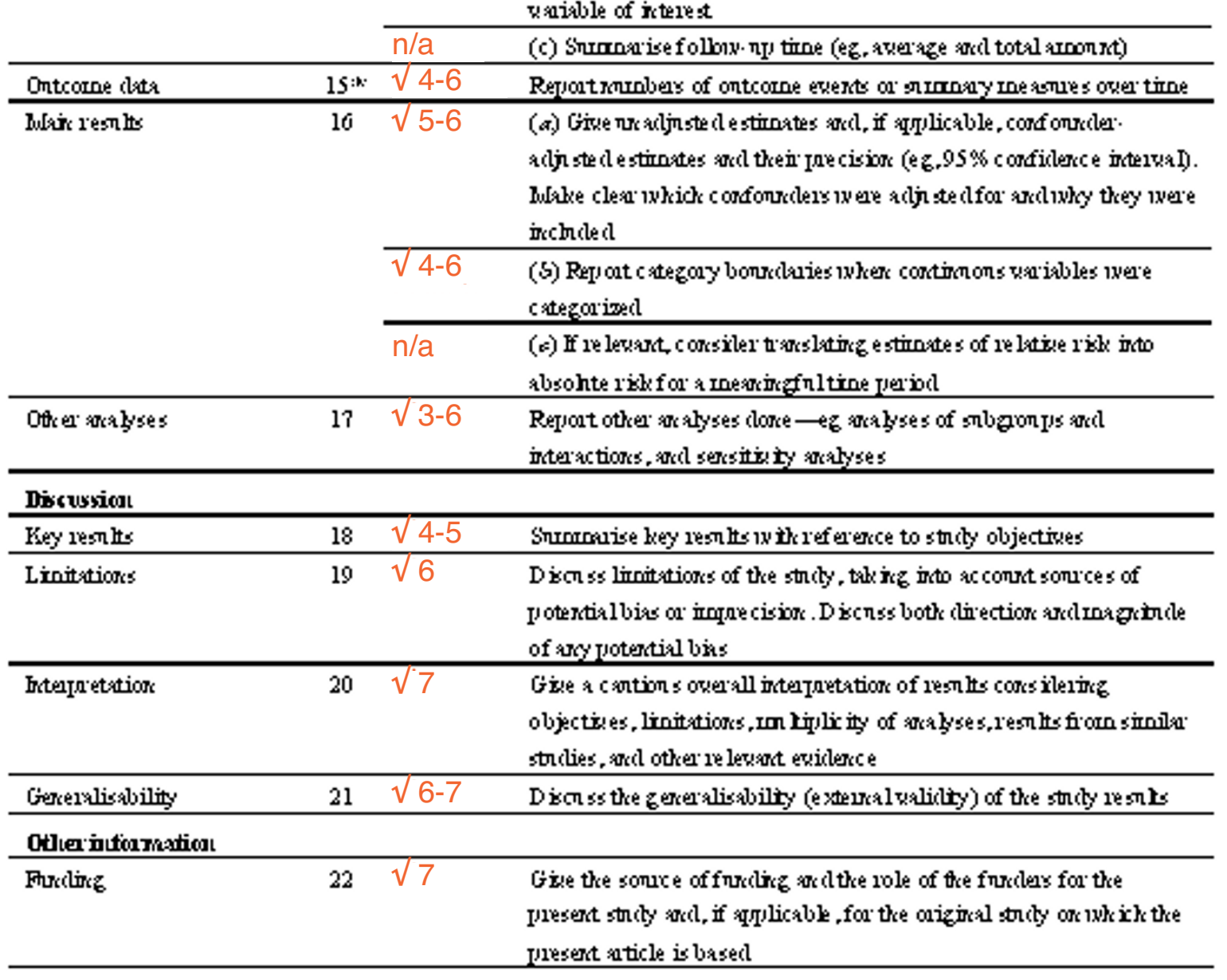

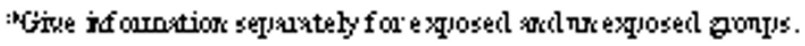

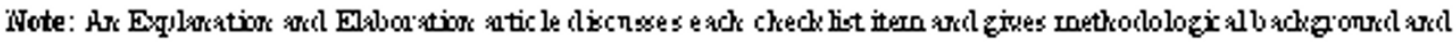

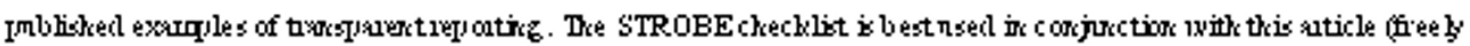

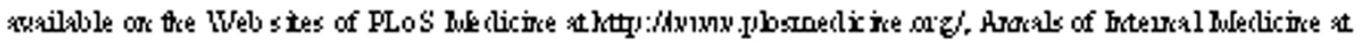

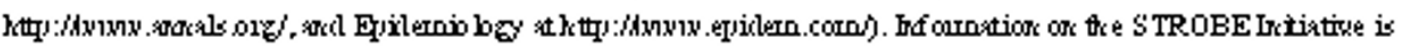

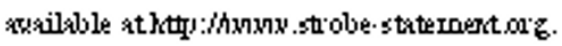

